\title{
CHEMISTORY: Integration of Creative Story Writing in Understanding Chemical Elements in Online Learning
}

\author{
Ryan V. Lansangan*, Karen S. Yoma, Caesar Anthony F. Yoma, Katherine Patrice B. Sibug, \\ Regene Marie Cabrera, Evelyn B. Gregorio, Frederick Roy A. Manubay
}

Junior High School Department, University of Santo Tomas, España, Manila, Philippines

*Author to whom correspondence should be addressed; email: rvlansangan@ust.edu.ph

\begin{abstract}
This work presents a pedagogical exploration of Junior high school teachers in drawing an integration between creative writing and chemistry concepts in understanding the behavior of chemical elements as means of addressing the competencies of the Science and English learning areas in an online instructional delivery. Titled A SHORT CHEMISTORY, this paper explores the expected skills, challenges, and opportunities in the possibility of integrating the two disciplines as an innovative way of developing engagement and comprehension among learners in a remote platform. Results uncovered that the said interdisciplinary performance task was pedagogically possible despite the challenges encountered by the facilitators and the learners. Adequate foundational knowledge of the lesson and skills associated with the expected output for both teachers and students, and the need for purposeful interaction and collaboration, are identified as the essential skills expected to attain the objectives of the integration. Teachers found it challenging to see the seamless integration of the chemical element's characteristics in the characters of the story through lack of depth of personification and time constraint. The integrated task paved the way for several opportunities for both teachers and students in terms of creativity, collaboration, and sense of fulfillment.
\end{abstract}

Keywords: chemical elements; creative writing; interdisciplinary tool; chemistry online learning; curricular integration and articulation

\section{INTRODUCTION}

The current landscape of education in the Philippines is a face of a paradigm shift brought about by the COVID-19 pandemic. It changed the way curriculum is planned, prepared, and executed in consideration of the limitations of the mode of instructional delivery and challenged educational institutions' organizational agility $(\mathrm{Wu}, 2020)$. Hence, educators shouldered the new ways of how the contents of the curriculum can be realigned to conform to the demands of the entirely new learning environment (Edelen, 2020) as they described it to be a quintessential adaptive and 
transformative challenge since there is no precedent to guide the execution (Reimers, et al., 2020) as it is linked with challenges and obstacles (Crawford et al., 2020). Nevertheless, the core of the students' needs never changed, and that is to acquire meaningful learning experiences.

As school communities embarked into the new era of learning, it equally demanded teachers with innovative and creative ways of delivering instruction without compromising the learning of the students and the priorities of the institution. Torquero (2020) raised the significance of improving the curricular practices and the usage of new instructional methods that will respond to the current context. Indeed, creativity and innovation in this crisis learning (Pace, Pettit, \& Barker, 2020) distorted the status quo and moved into learning that focuses on engagement, curiosity, and authentic knowledge construction (Redmond and Henson, 2020). And one thing was proven to be true, what worked in the usual face-to-face instruction won't work anymore in a flexible mode of instruction. There is a need to identify required essentialities of the teachinglearning process amid the pandemic and make the most of existing resources to transform the education into the alternative mode (Mishra, Gupta, and Shree, 2020). However, while students consider this alternative platform of learning to be interesting, modern, adequate, and convenient (Kedraka and Kaltsidis, 2020), they raised some challenges such as limited communication and socialization, lack of discipline and consistency (Putri, et al., 2020) and heavy workloads and fatigue (Niemi and Kousa, 2020).

In the Philippines, the Department of Education announced the utilization and recalibration of alternative learning strategies during the time of pandemic as the flagship of its learning continuity plan in response to the health crisis. In the said continuity plan, the curriculum was streamlined and focused mainly on the most essential learning competencies (MELCs) in which students are expected to be more adept in developing 21st century skills and contextualize their lessons into real-life situations (Lansangan and Gonzales, 2020). These competencies will serve as the guide of teachers in delivering instruction in consideration to their adapted platform and existing resources. But as expected, this calls for new practices across learning areas that encompasses the nature of instruction and assessment that are suitable to alternative modalities.

Chemistry as a discipline is not an exemption to possible instructional dilemmas that science teachers might face in the context of the new ways of delivering instruction brought about by the pandemic. Lansangan (2020) in his autoethnographic work uncovered in the gathered pedagogic data, the lessons, challenges, and opportunities associated in teaching chemistry in basic education in an online mode. It was consistent to the work of Mojica (2020) in his personal account of teaching chemistry in the epicenter of the COVID-19 pandemic. Among the challenges presented in the literature included developing and delivering engaging online instructional materials laboratory activities to approximate a hands-on experience (Lynn, et al., 2020); less coverage of curriculum content (Putri, et al., 2020); uncertainty that students might not understand the content because of the lack of visual cues (Tan, et al., 2020); assessment of learning; and presentation of concepts in consideration to the nature of chemistry having a specialized language and representations. Amidst these challenges in teaching and learning the subject, engaging students in the process should be the priority. In challenging times like this, especially in the remote set up of instruction where students are not with the teachers, focusing on the essential content and learning experiences of the students account as one of the effective ways of hooking the students to make the process of learning undisrupted. In the disruption of classes brought about by crises like this, students struggle to find a learning space that is peaceful and engaging (Potgieter, et al., 2019) and that they rely on the teachers to create such an atmosphere (Tigaa and Sonawane, 2020).

At the time of this writing, the authors are currently collaborating with the other learning areas, specifically the language teachers, on how to do the integration of creative writing and understanding chemistry principles to address the competencies on the characteristics and behavior of chemical elements. One of the effective ways of doing such is through an 
interdisciplinary approach. The idea of doing interdisciplinary tasks between science and other disciplines is not an altogether new one. One of the points for integration is interweaving stories and chemistry, which is a rare pedagogical resource in science classrooms (Fishman, 2020). The integration of the arts of writing and sciences is a challenging but promising approach for interdisciplinary learning (Kolovou and Kim, 2020). As cited from the work of Januchowski-Hartley, et al. (2018), it is a way of identifying approaches that can bring diverse perspectives and tools to foster creativity and strengthen the ability to overcome some of learning challenges. Although the conventional way of learning chemistry as a discipline is crucial for students to gain important concepts and skills, Furlan, et al. (2007) believed that some personal and creative experiences may not only give students enjoyment in learning chemistry but also add to their ability to learn the subject. Tournis, et al. (2020) described it as an excellent way to introduce complex phenomena in a simple, entertaining, and engaging package. Although the areas of creative and scientific writing come from different entities with different objectives, conventions, and language, integrating creative writing into science pedagogy is a promising and increasingly prevalent strategy (Gillen, et al., 2020). Since chemistry involves technical terms of chemical substances and that they abound in the extensive list of technical literatures, Schettino (2014) agrees that there are alternative ways to communicate when scientists share it to the general audience or when writers approach chemistry as an inspiration or metaphors of more complex human realities. As cited by Schettino (2014), a reference point that pioneers this idea can be found in the work of Primo Levi, a successful chemist and writer, where his professional experience in science was transferred into writing through the interweaving of chemistry and fiction.

Several studies have attempted to draw a line in the integration of chemistry with other learning areas and disciplines. In his work about merging poetry and chemistry, Alber (2001) believed that finding ways to draw connections between chemistry and other disciplines is worthwhile. Kolovou and Kim (2020) introduced integrative drama-inquiry learning, which exemplifies the teaching of science through drama and revealed its significant impact to students' intrinsic motivation. Injecting drama in understanding electronegativity and chemical bonding, Danckwardt-Lilliestrom, et al. (2020) uncovered that creative drama in chemistry education enhances student agency in their exploration of chemistry concepts and principles while Bradbury (2014) concurred it to improve the student's academic outcomes both in science and language arts.

In the exploratory research conducted by Yang, et al., (2014), it revealed that the imaginative writing process of science students in understanding a particular science content follows a process from retrieving information, generating ideas, and integrating the retrieved information with the ideas on writing. Moreover, Gillen, et al., (2020) explained that to write effectively and creatively about science requires a deeper understanding of the underlying scientific concepts than traditional examinations. In research on pedagogy, the word "remix" is used by Knobel \& Lankshear (2008) and Freire \& McCarthy (2010) as a means of creating cultural artifacts to create a new blend of works, which is guided by participatory learning model where students create their own works focusing on their voices and creative expressions. It takes into multiple forms such as mashups, memes, parodies, and deconstructions (Navas, Gallagher, \& burrough, 2018). It was supported by Morris \& Stommel (2018) as a critical digital pedagogy. Redmond and Henson (2020) identified four implications in adapting remix in the teaching and learning process: learner-centered, democratic, and human; simple, durable, flexible, and responsive to teacher control; cultivates complex, higher order thinking; and paves way for innovation. Loomis (2019) raised remix to support multiple student learning styles.

With these theoretical underpinnings and implications, this paper sought to present a pedagogical exploration of Junior high school Chemistry and English teachers in drawing an integration between creative writing and chemistry concepts in understanding the behavior of chemical elements as means of addressing the competencies of the Science and English learning areas in an online instructional delivery. The pedagogic data in this paper narrates the development of the 
interdisciplinary performance task. A performance task (PeTA) allows learners to show what they know and are able to do in diverse ways by creating or innovating products or do performancebased tasks (DepEd, 2015). This is an innovative opportunity in conceptualizing meaningful learning experiences that heighten students' engagement and motivation in learning chemistry in an alternative mode of instruction. Further, this collaborative inquiry points out the lessons learned, challenges encountered, and opportunities ahead in the possibility of interweaving creative writing and chemistry contents in an integrative performance task.

\section{METHODS}

The pedagogical procedures executed in the completion of the task were implemented in the context of flexible instructional delivery using an online platform during the time of COVID-19 pandemic in the country. The locale of the study is a co-educational private sectarian Junior High School in Metro Manila, which is currently in its second quarter of the academic year 2020-2021 adapting blended online learning where students participate in synchronous classes 2 hours per week and 3 hours asynchronous per week (for English and Chemistry subjects). The school is using Cloud Campus (CC), a cloud - based infrastructure powered by Blackboard, a world - class learning management system (LMS), maintained by the school's Educational Technology Center, and enhanced by Google for Education. The exploration of the proposed performance task was administered to the entire Grade 9 students at the school but this paper focuses the observation to 92 Grade 9 students with age range of $14-15$ years old consisting of $45.65 \%$ boys and $54.35 \%$ girls. Informed consent was secured in the post-assessment stage of the task where the students answered open-ended questions pertaining to their experiences in doing the performance task. The entire scope of the development of the integrated performance task is divided into four successive phases: instructional planning, execution phase, assessment of the outcome, and focus group discussion phases.

Phase 1. Instructional Planning. This initial phase involves the mapping of the necessary curricular contents and competencies relevant to the instructional plan. It is divided into two subphases, the articulation and integration session and instructional meetings with the subject teachers involved. The articulation and integration sessions are regular curricular meeting among the different learning areas in every grade level to articulate the contents to be covered in the upcoming quarter and map out possible points for integration whether in terms of skills, contents, and product or performance. Using the MELCs (most essential learning competencies) as basis, the science pointed the competency on predicting the behavior of an element using the periodic table of elements (S8MT-IIIi-j-12) while the English learning area raised the competency on analyzing literature as a means of understanding unchanging values in the VUCA (volatile, uncertain, complex, ambiguous) world (DepEd, 2020). Having a challenge in the actual transfer of chemistry learning by actual practical applications in an online instruction, chemistry teachers ventured into exposing students to alternative means of assessment about chemical elements and make use of them through creative writing incorporating the different elements of short story to highlight and process in their mind the gained information about elements.

After agreeing with the possibility of the integration of the learning outcomes between the subjects involved, it was followed by another instructional planning between the English and Science teachers. This session involved identifying areas of concerns between the two disciplines and setting the common grounds that need to be supervised in the actual execution. This included analyzing the competencies, the time frame of the completion, the rubrics to be used, monitoring of students' output, and assessing the students' final output. Merging the purposes of the two disciplines, a performance task proposal was prepared and A SHORT CHEMISTORY was finalized as the expected output of integration. This is an individual output that will be completed by the learners for 6 weeks. 
Phase 2. Execution. The execution started with the orientation to the students in the beginning of the quarter to set the direction of the interdisciplinary output. The science and English teachers conducted their respective orientations after coordinating with one another and identifying areas to be emphasized by each discipline. The actual orientations were recorded in the videoconferencing platform being used by the school. Prior to the completion of the final output, students were tasked to make two "mini tasks", which will serve as the interim deliverables of the final performance task. These outputs were submitted both to the chemistry and English teachers for critiquing.

Mini Task 1 deals with the character profile of the assigned element to the student, which includes image of the element, physical and chemical properties, background information, particle description, electronic structure, position in the periodic table, periodic properties and uses and applications. The students were tasked to conduct research and advance reading about the concepts and validate them during the synchronous discussion. All these information are the contents of the lesson outline for the quarter. Stipulated in the said task are guide questions given by the English teachers such as how the element looks like as a character, context, and interesting things about the element, physical appearance of the character, description of the behavior, etc.

Mini Task 2 is the plot summary where the information that they gathered in the character profile will be applied. Guided by the English teachers, students were asked to provide the different elements of the short story using a graphic organizer. This will serve as their guide in writing the short story. This includes plot, conflict, point of view, characters, theme, and setting. Communication between the integrating teachers was maintained using group chat where they can share their instructional experiences in the conduct of the performance task.

Phase 3. Assessment. This phase included the assessment of the students' final output. To assure the originality of the students' work, a plagiarism checker programmed in the school's learning management system (LMS) was used. Using the rubrics in the LMS, the chemistry teachers looked into the aspects of personifying elements as characters, utilization of other chemical elements as supporting characters to highlight the behavior of the assigned element, comprehensive use of the concepts in the mini tasks, story plot conveying the properties of elements, creativity and punctuality. On the other hand, the English teachers focused on the literary and creative elements in short story writing, particularly on how the property or properties of the prescribed element given to each student can be properly depicted into the story's character, how the assigned element's property can be translated into a personality trait, and from this personality trait create a probable plot, and how to use literary devices to further enhance their writing.

Phase 4. Post-assessment activity. This culminating phase of the interdisciplinary performance task included asking open questions to students and focus group discussion among the teachers involved to identify the skills, challenges, opportunities, and other aspects for further improvement of the said integration. The focus group discussion was facilitated through virtual platform using Zoom while the gathering of the responses in the open-ended questions were done through google forms.

As a means of evaluating the conduct of the performance task, qualitative and quantitative data were gathered using google form. In the analysis of the data, responses in the quantitative data were reported in frequencies while responses in the open-ended questions underwent thematic analysis, which involved identifying emerging categories. Letters were used to identify the respondents, $\mathrm{S}$ for student cohorts and $\mathrm{T}$ for teacher cohorts. In vivo coding was employed to come up with the themes that will represent the responses of both teachers and students. The results of the inquiry present the lessons learned, challenges encountered, and opportunities associated in the conduct of the integrated performance task. 


\section{RESULTS AND DISCUSSION}

This discussion covers the assessment of the pedagogical processes associated with the completion of the output and its implications. This includes sample of student's output, which include the genres, common characterization of elements, assessment of the different components of the output; the students and teachers' skills drawn from the context of their experiences in facilitating the performance task integration; the challenges encountered; opportunities that paved the way for meaningful teaching and learning; and recommendations in refining the processes.

Sample Student's Output. Below is a sample student mini task output that summarizes the plot of the story. In the plot summary, Mr. Walter and Lithia's interaction represents Lithium violently reacting with water. Since Lithium is a very reactive element and tends to easily lose its outermost electron, the main character was described to be somewhat paranoid, impulsive in decision making, docile, and sensitive. The character was physically described as with eyes ablaze with red irises referencing from the color of the flame of Lithium.

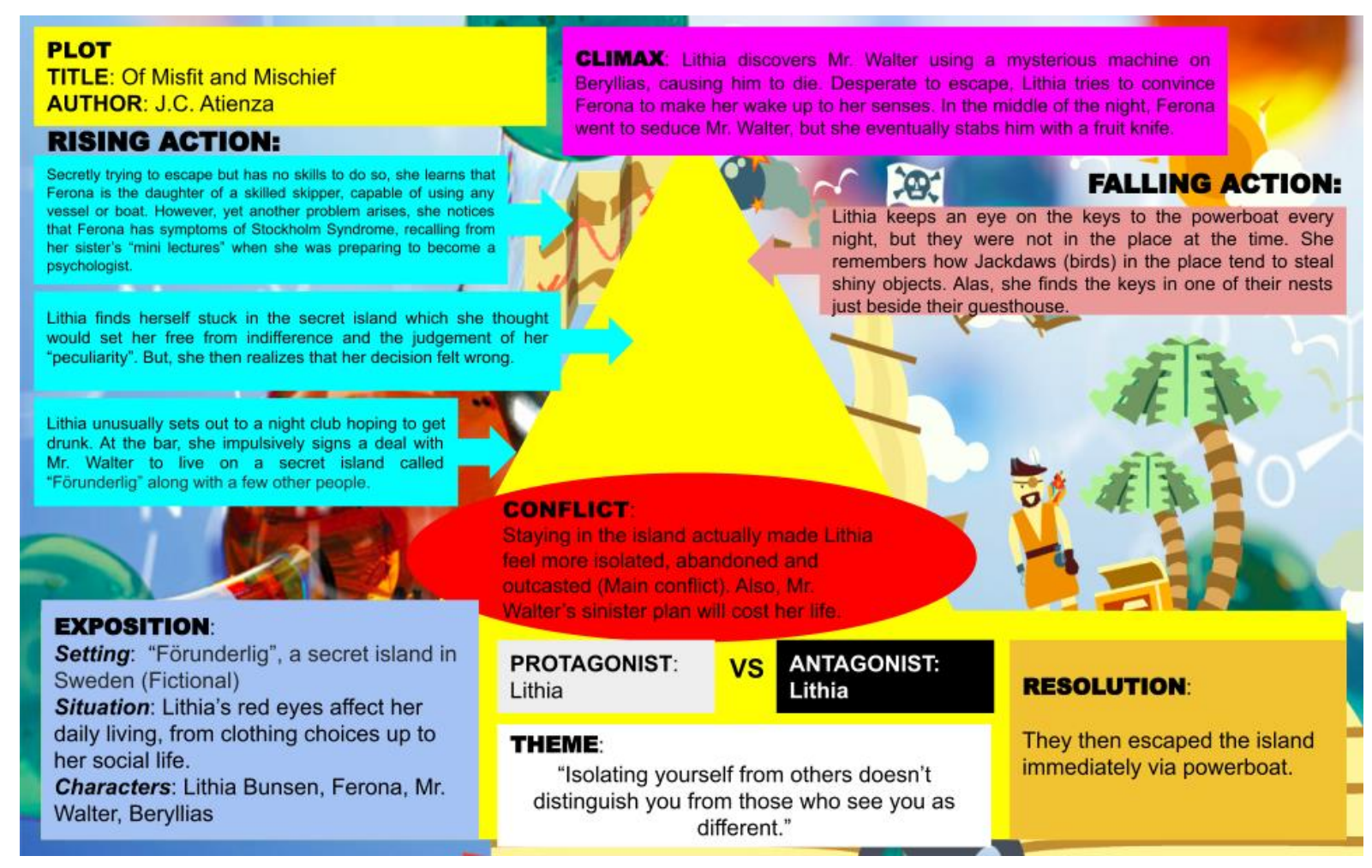

Here is the synopsis of the story:

After Lithia Bunsen's well-kept peculiarity, her eyes, which are ablaze like the red flame emitted by Lithium, makes her fail to secure a decent job, she signs an agreement with Mr. Walter to live on a secret island called "Förunderlig". As her longing and days grew longer, she unceasingly attempts to break free, but was met with two more dilemmas. Her conveyance and how to steer it. Eventually, she learns that an acquaintance residing on the same island, named Ferona, could be of a great deal to her scheme. Unbeknownst to the both of them, Mr. Walter had already laid a step of his vile and iniquitous plot, much like the violent reaction of fizzing between Water and Lithium. Will she be able to escape? 


\section{OF MISFIT AND MISCHIEF}

$$
\text { J.C. ATIENZA }
$$

Twas the eleventh time since poor Miss Lithiana Augusti Bunsen, Lithia as she prefers to be called, had failed another job interview. She went out in her usual ensemble, in a plain dress and stilettos, not to mention her essentials: a pair of huge sunglasses along with a wide-brimmed boater hat resembling a dome - this time, all in black- - to conceal her most profound secret. The assessor already had her blood boiling after having her overpriced cashmere coat covered with coffee, an assault from her forerunner.

“Ojdà! Miss Bunsen, aren't you?--the interviewer said with a baffled look. Well, don't have all the hens at home. This is a job interview for an Arts teacher, not an audition for Breakfast at Tiffany's."

“Ah, yes. I’m quite well aware of that," Lithia replied while politely removing her hat.

"Hmm... Could you even care to remove those damned sunglasses?" the interviewer uttered in exasperation while looking through her documents.

Ms. Bunsen had already laid her spectacles, for which she remained in anguish-stooping down, avoiding the evaluator's gaze at all costs.

"You seem to have -" the interviewer suddenly paused, lost for her words.

Aghast, she had become fixated in a shared glance, as if she was trapped in a red sun with an eerie glow, radiating an oppressive warmth, which in time, evokes even the slightest of irritation to absolute madness. As the interviewer continually delved into Lithia's eves, both in wonder and fear of its eccentricity, she had failed to rule over ambivalence and conjured a curt remark.

"Surely, the kids will make fun of you, creepy red-eyes! Next!" the interviewer whispered before calling out the next applicant.

Failing that interview was the last thing she thought would make her day more horrid than any other. Until one strikingly shocking idea had crossed Lithia's mind - she felt the urge to party. Quite uncanny, for a loner who spends most of her days poring over ornithology books, sipping a cup of coffee, and lounging around her small garden-and worse, for that loner is now unemployed.

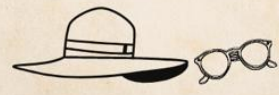

Just a few meters across the left of her dreary alley, there stood a nightclub barely lit with a sign, bearing the word: "Sugen". Bunsen, who was not aware of its existence nor had any experience of what a nightclub is, hurriedly went for the bar. There, she seemed to have noticed a man whose face is of some familiarity. He had a long crooked nose with a droopy nasal tip and a potbelly that barely fit in his dapper blue plaid suit and bowtie. As Lithia continued to peer through the straggling crowd, she had Filed to notice that the man had gone for her. Abruptly, he sat beside Bunsen and said:

“Halla, you must be new here," he presumed nonchalantly.

"Ah... ye-yes," she stuttered half-drunk, while anxiously avoiding his gaze.

"Ảh kära, det måste ha varit svårt att ta in," the man said in a pitiful tone. Oh dear, it must have been hard to take in.

"Pardon?" Lithia asked in annoyance, while quickly turning her head towards his direction. She then pulled out her gigantic eyewear, flared up her red suns to the man, and looked at him through and through the soul. However, something felt off. The atmosphere was unlike any other. The wind never felt so cold until that very moment. There, the man stood idle, as he seemingly was not affected by her peculiarity in any way. The next words he uttered prompted gooseflesh in Lithia.

"I am no stranger to your secret-he said in crossed arms. It must have been hard living like that, suffering alone in remorse and shame. Not having the chance to explain yourself before people who don't even know a bit of you. Going out every once in a while inside those clothing, deliberately aware that in one way or another, people will remind you of your insecurity."

"But-" Bunsen gasped in disbelief.

“Let me help you. Come with me to my island, Förunderlig. There, I guarantee that you'll feel a grea deal safer and free from indifference than here. I can even provide you with a room and other necessities without paying. Just sign this agreement--the man said with conviction. You can call me as Mr. Walter, by the way.

Despite the deal looking folly, Lithia proved desperate, and somehow-drunk enough — to sign the paper immediately.

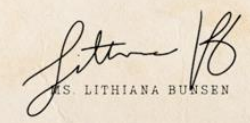

Setting forth the southeast coast of Stockholm to Förunderlig, she needlessly brought her essentials, as well as a couple of books and a telescope. From there, she acquainted two more people who had several well as a couple of books and a telescope. From there, she acquainted two more people who had several
quirks of their own. There was a young lad who wore a plaid gray suit and tie with black leather gloves, named Beryllias, and a woman in her 20 's who wore a long and form-fitting pair of bell-bottom pants, a chestnut linen waistcoat, and a wide-brimmed black hat. The former only has four fingers on each hand and glows porcelain white when uncomfortable, and the latter has extraordinary skin, which easily becomes elastic and loose as if it is melting when exposed to the scorching heat of the sun.
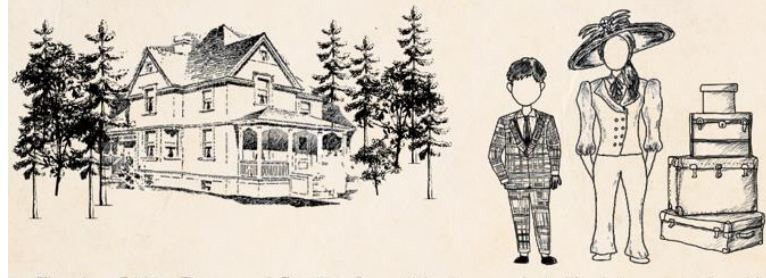

Together, Lithia, Ferona, and Beryllias fancy their time mostly in

When there was no more avifauna nor flora left to observe during the barren of winter, time in the secret island seemed to grow frozen and lonesome cold for Lithia. Her scarred heart, of which the cruel wind and white snow covered with marks of resentment, craved the warmness of spring morning. The withered flower path, which she regrets to have taken, has resulted in a broken fate she cannot undo. On the night of her discernment, she discovered that only the fire of grit is her chance to bloom again.

To do this, she relentlessly rummaged through every nook and cranny of Förunderlig to seek Mr. Walter's speedboat and its keys, avoiding even the slightest skepticism from her company by setting out during dusk. Her clandestine intent transpired ultimately - but her plan to escape was seized by another dilemma. Her inability to operate the machine.

"Could you give me a tour around the island by boat? It seems like I haven't seen any more animals yet" Lithia asked Beryllias while enjoying her breakfast.

“Perhaps Ferona could. Mr. Walter is very close to her and is privy to everything here," Beryllias kindly replied.
Bunsen's desire to escape requires her to take Ferona, willy nilly. But her hesitation built up as Lithi noticed that Ferona was acting rather strange and too emotionally-inclined when it comes to M Walter. In the afternoon, she opted to talk to the boy and tried to know more

"To tell you the truth, Ferona was kidnapped and taken here before I voluntarily did. It probably has been years ever since," Beryllias whispered cautiously.

"Why? What's the reason why Mr. Walter took her?" she whispered in disbelief.

Their conversation was abruptly interrupted because Mr. Walter had called the young man

Meanwhile, Bunsen pondered heavily as she was somehow familiar with the case, victims creating bonds with their captors. At last, she remembered that her now-psychologist sister taught her a thing or two back then about what is called the "Stockholm Syndrome". What she knew about it was her only chance left to escape. And so, she tried to waken up Ferona's senses with those convincing methods.
lack

In the twilight, as Lithia scanned through the center hall that was embellished with fin de siecle paintings, she overheard lingering mumbles and grumbles that filled its walls. At first, they were fain and indistinct, as she insinuated to and fro the source-asudden, there sounded a loud thump, and another, preceding raucous sounds of electrocution resonating from a hidden room to the left Bunse had immediately rushed to the nearest leeway, in the kitchen, grabbing anything she could find to avoid suspicion - an apple and a fruit knife.

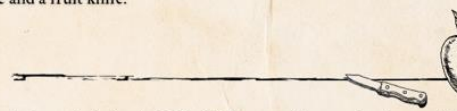

As soon as the blade had touched the rind, Mr. Walter casually waved and passed by in a quickie before heading to his suite. Curious, Lithia was taken aback and retraced his steps. Eventually, she found secret entrance leading to an old and restricted foyer, where she found the young Beryllias inside a large enigmatic machine, bereft of life. In shock, she forthwith sought for the keys to the speedboat, but they were not in the usual spot.

In the same moment, Ferona entered Mr. Walter's room, channeling her innermost sultry, tempting him with her alluring aura, and partially teasing him of her voluptuousness. She gave the old man quite a sensual experience, until slowly, cautiously, and unbeknownst to him, the woman whom he supposed would untie her undergarment, suddenly cried: 


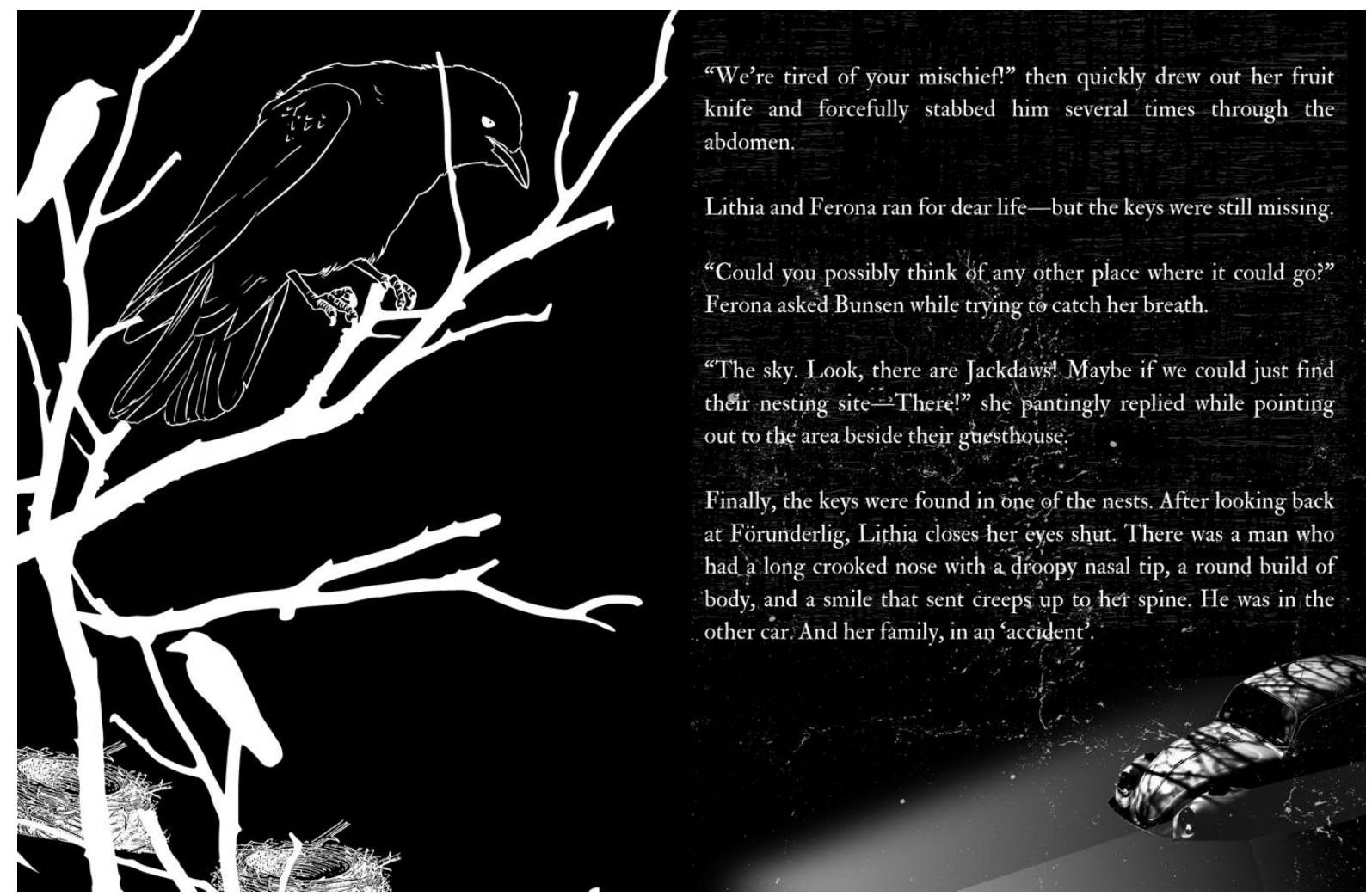

With regards to the different genres of the stories written by the students, Table 1 presents the frequencies of the different themes employed by the students in their output. Majority of the output deals with romance accounting for $27.17 \%$ of the outputs followed by mystery or crime $(16.30 \%)$ and suspense and thriller (10.87\%).

Table 1: Common Themes of Students' Output (n = 92)

\begin{tabular}{|l|c|c|c|c|c|}
\hline \multicolumn{1}{|c|}{ Theme } & $\boldsymbol{f}$ & $\mathbf{\%}$ & Theme & $\boldsymbol{f}$ & $\mathbf{\%}$ \\
\hline Romance & 25 & 27.17 & Friendship & 5 & 5.43 \\
\hline Mystery/crime & 15 & 16.30 & Historical & 3 & 3.26 \\
\hline Suspense/Thriller & 10 & 10.87 & Fantasy & 3 & 3.26 \\
\hline Family Saga & 8 & 8.70 & Comedy & 2 & 2.17 \\
\hline Adventure & 7 & 7.61 & Slice of life & 1 & 1.09 \\
\hline Science fiction & 6 & 6.52 & Teen fiction & 1 & 1.09 \\
\hline Drama & 6 & 6.52 & & & \\
\hline
\end{tabular}

Tabulated in Table 2 and Table 3 are the other examples of elements portrayed as protagonists and antagonists respectively in the short story written by the students. This characterization is based on the profile of the pre-assigned elements studied by the students in the first mini task, which includes historical background, particle description, electronic structure, position in the periodic table, and periodic properties. From the data and series of consultation with the teachers, students chose properties of these elements that will serve as the inspiration in writing their short stories. 
Table 2: Some of the Chemical Elements Portrayed as Protagonists in the Story

\begin{tabular}{|l|l|l|}
\hline \multicolumn{1}{|c|}{ Element } & \multicolumn{1}{c|}{ Character } & Property \\
\hline Aluminum & Kind student & Non-toxic \\
\hline Argon & Anti-social student & Inert \\
\hline Barium & King & Reactive, Multipurpose and Expensive \\
\hline Bromine & Superstar & High electronegativity \\
\hline Calcium & Soldier & Ductility \\
\hline Chlorine & Rich CEO & High electronegativity \\
\hline Copper & Influencer & Conductivity \\
\hline Gold & Rich but humble girl & Soft and dense \\
\hline Iodine & Dual Personality & Ability to change in color when heated \\
\hline Iron & Fashion Model & Malleability \\
\hline Phosphorus & Twin sisters & Red and white phosphorus \\
\hline Platinum & Late blooming star & Precious metal \\
\hline Silver & Hardworking Student & Malleability \\
\hline Sulfur & Strong Personality & Strong acid \\
\hline Tungsten & Strong Woman & High melting point \\
\hline Titanium & Hero & Resistance to corrosion \\
\hline Tin & General of the soldier & Resistance to corrosion \\
\hline
\end{tabular}

Table 3: Some of the Chemical Elements Portrayed as Antagonists in the Story

\begin{tabular}{|l|l|l|}
\hline \multicolumn{1}{|c|}{ Element } & \multicolumn{1}{c|}{ Pharacter } & \multicolumn{1}{c|}{ Property } \\
\hline Arsenic & Evil friend & Poisonous \\
\hline Boron & Envious co-influencer & Toxic and irritant \\
\hline Bromine & Bully & Reactivity \\
\hline Chlorine & Lover turned cheater & Toxicity \\
\hline Fluorine & Bully & High electronegativity \\
\hline Fluorine & Killer butler & Reactivity \\
\hline Fluorine & Crime lord & High electronegativity \\
\hline Helium & Possessive friend & Low boiling point \\
\hline Iodine & Corrupt politician & Changing color when heated \\
\hline Iron & Weak friend & Corrosiveness \\
\hline Mercury & Violent and hostile & Poisonous and deadly \\
\hline Silver & Jealous model & Luster \\
\hline Sulfur & Manipulative government official & Enemy of copper \\
\hline Xenon & Model student & Stable configuration \\
\hline
\end{tabular}

Assessment of Students' Chemistory Output. Presented in Table 4 are mean scores of the students in the different components of the performance task. The listed components in assessing the students' output were deliberated by chemistry teachers based on the competency on predicting the behavior of an element using the periodic table of elements and the expectations of the integrated performance task. These scores were assigned to students' submission and generated from the rubrics embedded in the LMS. A score of 8 is set as the perfect score per component following the gradation in the used rubrics. 
Table 4: Mean Scores of the Assessment of Students' Output (Chemistry Component)

\begin{tabular}{|l|c|c|c|}
\hline \multicolumn{1}{|c|}{ Components } & X & SD & S \\
\hline $\begin{array}{l}\text { Utilization of Elements as Supporting } \\
\text { Characters to Predict the Behavior of } \\
\text { Element X (8) }\end{array}$ & 6.50 & 0.97 & $\mathrm{~S}$ \\
\hline $\begin{array}{l}\text { Characterization of Elements' } \\
\text { Properties in the Story (8) }\end{array}$ & 6.01 & 0.85 & $\mathrm{~S}$ \\
\hline $\begin{array}{l}\text { Comprehensive Use of the Element } \\
\text { Information in the Mini Task (8) }\end{array}$ & 6.41 & 1.01 & $\mathrm{~S}$ \\
\hline $\begin{array}{l}\text { Story Plot Conveying the Properties of } \\
\text { Elements (8) }\end{array}$ & 7.14 & 1.09 & \\
\hline $\begin{array}{l}\mathrm{x}=\text { mean, SD = standard deviation, Q = Qualitative Description (E - excellent, S = satisfactory, U = unsatisfactory, P= } \\
\text { poor) }\end{array}$
\end{tabular}

Representing the attainment of the learning competency, it can be deduced from the table above that a satisfactory score in all the components was demonstrated by the students' output with the story plot conveying the properties of elements having the highest mean score of 7.14 while the characterization of the element properties had the lowest mean score of 6.01. In terms of the utilization of elements in predicting the behavior of elements, satisfactory is assigned when elements in the story were used as characters to highlight the behavior and characteristics of the elements. In terms of the characterization of elements, satisfactory was achieved when elements are clearly named and described in the story and will give readers the idea of what the characters looked like. And in the plot, satisfactory rating of the students' output pertains to the appropriateness of the plot in bringing the character to life through a story.

Reflected in Table 5 are the components assessed by the English teachers in the output. From the data, the writing process got the highest mean score of 9.88, which describes students' sufficient time and effort to the writing process (prewriting, drafting, reviewing, and editing). This also includes good grammar, correctness of sentence structure with few errors on punctuation and capitalization. The characterization, with a mean score of 9.67, assessed how the learners translate the characteristics of the elements into the story with some convincing traits of the character similar to the prescribed element. A mean score of 8.85 was given to the organization of the plot, which assesses clear transitions in the story. The use of literacy devices got the lowest mean score of 6.00 , which deals with the use of creative details from students' imagination.

Table 5: Mean Scores of the Assessment of Students' Output (English Component)

\begin{tabular}{|l|c|c|c|}
\hline \multicolumn{1}{|c|}{ Components } & X & SD & Q \\
\hline Characterization (10) & 9.67 & 1.92 & S \\
\hline Writing Process (10) & 9.88 & 2.50 & S \\
\hline Organization of the Plot (10) & 8.95 & 1.85 & S \\
\hline Use of Literacy Devices/Creativity (10) & 6.00 & 1.94 & S \\
\hline
\end{tabular}

$\mathrm{x}=$ mean, $\mathrm{SD}=$ standard deviation, $\mathrm{Q}=$ Qualitative Description $(\mathrm{E}-$ excellent, $\mathrm{S}=$ satisfactory, $\mathrm{U}=$ unsatisfactory, $\mathrm{P}=$ poor)

Students' and Teachers' Skills Drawn from the Execution of the PeTA Integration. Foundational Knowledge and Skills Associated to the Integrating Subjects. This aspect dwells on the skills needed for the successful implementation of the integrative task based on the views of the teachers and the learners. Teachers' responses primarily identified adequate knowledge of the lesson, the need for purposeful interaction and collaboration, and the essential skills expected to attain the objectives of the PeTA integration. For the first one, teachers emphasized the importance of being equipped with the necessary base knowledge for their respective subject areas - the properties of elements in the periodic table for Science and the elements of a short 
story/literary devices for English, not only in preparing the students for the activities and tasks involved in the integration, but also on the necessary know-how in assessing and grading outputs effectively and appropriately.

It is also deemed to be helpful if there is some basic knowledge and understanding of the concepts from the collaborating subjects, like the English teacher knowing the basic aspects of scientific elements or the Chemistry teacher knowing about the parts of the short story plot. This equips both teachers to be able to present and explain the various aspects of the performance task and mini tasks proficiently. As T5 shared,

"Teacher must be knowledgeable when it comes to the different properties of elements in the Periodic Table (in my case, I did some research especially for elements that are not too common), to fully assess student's personification of their character element, and the teachers must have futuristic vision since most of the characters are sci-fi." In addition, T6 affirms the said notion that, "As a subject teacher, skills in teaching literary devices and the elements of a short story and checking if these lessons are present and properly applied to the final output. It is also necessary for the subject teacher to try and at least understand the scientific element itself to see if it was appropriately personified in the story."

It was likewise important to note that both the Chemistry and English teachers must have at least intermediate grammar skills and ample reading comprehension to be able to communicate the goals and objectives of the PeTA, advise and make suggestions during consultation, and evaluate the progress of the students. Helmane and Briska (2017) underscored the inner balance of the integrating subjects must be pointed out to attain the aims and expected tasks of the individual subjects. The balance between the two is affirmed by $\mathrm{S} 2$,

"Some of the expected skills in this PeTa are having knowledge about how to integrate the element to a living person, creativity and wit, correct grammar, and correct information about the element assigned."

Giving Feedback and Initiating Consistent Communication. Regarding the need for purposeful interaction and collaboration, the teacher-respondents pointed out that they must convey the purpose and objectives of the integration consistently in accordance with the level of comprehension among students. This means that they expect themselves to be patient and accommodating, providing time and expertise to assist, and fully assess the students' performance leading to the creation of quality and acceptable outputs. The consistent provision of feedback in the mini tasks and entertaining students' misaligned understanding of the integration must be communicated well by the teachers to address ongoing misconceptions while the completion of the story is ongoing.

Rootman-le Grange et al (2018) points out concerted communication of the teachers to the students to sustain the collaboration between the integrating disciplines. In fact, S1 points to the use of consistent communication as crucial in the process

"For me, the skills that are expected to have a meaningful experience in completing the integration task are time management and communication. We should plan our task earlier so that we have more time to think more carefully about our output. In addition, we also need to have the skill of communication especially to our teachers. I think that communicating to our teachers about our outputs gives us a deep understanding of what we're doing." 
Challenges Encountered by the Teachers and the Learners. Shallow Characterization. Teachers found that the students' outputs lacked the depth of personification of the element that was expected from their outputs. It was a common observation that students were not able to properly utilize the features of the element and translate into an effective character. Moreover, teachers found it challenging to see the seamless integration of the element's characteristics in the characters of the story. They have observed that character traits appear either too literal or too shallow. T1 concurs,

\begin{abstract}
"My students had a hard time interpreting elements into characters. Some outputs were able to reach the objective of the integration in Mini Task 2 but failed to properly execute it in a full story. Only the physical characteristics were considered in the characterization." S1 affirms the experience, "Simply, how the story will be written was completely affected due to the struggle of finding or integrating parts of the story that were somehow scientifically correct."
\end{abstract}

The expectation of seeing a literary interpretation of the element was not met by most of the outputs. The teachers attribute this to the lack of information from the research stage of the task as well as the lack of consultation initiative on the part of the students. Such challenges manifested itself even in Mini Task 2 that was also read by the Chemistry teachers. Even more challenging was the characterization present in the full-length story presented to the English teachers. Hu et al (2021) recognized the role of storytelling in science education, yet its application in practice is impaired by the fact that writing stories of abstract entities is difficult and a tough process. In the task completed by the students, they employed imagined stories to address the promotion of their understanding of the content (Engel et al., 2018). As attested by S4,

"I think it was pretty difficult to come up with a storyline because of course, making a story is not easy and coming up with a storyline that also relates to chemistry made it more challenging for me as a learner of Chemistry in English."

While some stories were able to show consistency from character to plot, most stories struggled to keep the organization of the storyline because characterization was prioritized. It is also important to note that teachers felt that creativity was inhibited because of the restrictions brought about by the guidelines of the task. After all, they had to stick with the features of the element and revolve the story around such a character. Meanwhile, students pointed out the challenging experience they had while making the plot summary. Striving to achieve a balance between the two integrating subjects, some of the students found it difficult to write a plot in the context of science. Though still posing a challenge to write, students found Mini Task 1 a helpful tool in constructing their plot summary. This is associated with Hu et al (2021)'s description as well- structured personification which involves the direct identification of the science concepts and that it significantly promotes students' understanding.

Time Constraint. Teachers and students consider time as a very crucial factor in achieving success in the implementation of the performance task. Even the skills required and the difference of the contents between the two subjects, more time is needed to address the required elements of the task and to guide the students in doing it. It is important to recognize that the implementation of the PeTA was done following the allotted number of days in the quarter as prescribed by the school. Online learning being a new platform for both teachers and students affected how much time was given in the different aspects of the performance task. S1 pointed out that,

"The challenges that I encountered in this kind of PeTA integration are lack of time and having a poor understanding of the mechanics. Although despite that, I was able to overcome these challenges." 
Similarly, S2 considers the limitation of time as the restricting factor in the execution of the task,

"The primary concern really is the limitation in terms of time. As much as I'd want to make the experience a more enriching and explorative one, the calendar for the second quarter made this impossible. What I wanted to have is inject more literary activities to aid the students in expressing themselves more."

Opportunities for Meaningful Teaching and Learning. Despite the challenges outlined, teachers and students perceived creativity, collaboration, and sense of fulfillment as the opportunities associated in the overall experience of the integration activities.

Space for Creativity. Teachers and students considered this learning opportunity as a creative way of exploring the different aspects of teaching and learning. It's an all-new experience for teachers to embark into a new way of assessing students' learning through integration. Exploring the contents and skills beyond the respective disciplines, teachers themselves became creative in addressing students' queries in the plot of their stories and in giving feedback to improve the tasks. As T2 shared,

"I enjoyed venturing into this altogether new experience. This peta integration challenged me to think of the what-ifs and how-tos of merging Science concepts with English writing skills. Additionally, this peta integration is a good model for them to show the students that teachers also practice what we ask them to do. Also, the concept of risk-taking is noteworthy since teachers are forced to navigate an unfamiliar territory which is exciting and somewhat nerve-wracking at the same time. Usually, teachers would resort to time-tested and classic ways of assessing their students. But with this fresh venture, teachers were put to test --- to deconstruct their old knowledge and ways and reconstruct with new knowledge."

Similarly, students tested their creativity in fulfilling the points for integration. They had to make use of their imagination as they took into consideration the concepts of chemistry and their short story writing skills in English. S4 reflected,

"While I was doing the PeTA. I actually discovered that I could be creative, and I could continue to finish a story because I enjoy writing but my mind sometimes gets so crowded with thoughts for what I want to write which eventually resulted for me to not finish writing but this PETA made me realize that I'm capable of keeping my thoughts on track. I also learned that creativity cannot be forced and should not be forced for me to make a relaxed, colorful and creative output.

Space for Collaboration. Teachers' experiences in the different aspects of the PeTA paved the way for collaboration and exchange of ideas while executing the task. This pedagogical exploration immersed them in a community of learning and practice among colleagues in terms of designing innovative assessment strategies while addressing the competencies intended for the learners. This is supported by T3,

"...the idea of collaboration and cooperation must be imbibed by the teacher first before we ask our students to do group activities because, in a way, we put ourselves into their shoes and understand more how group dynamics work."

Collaboration between teachers and students through establishing a rapport and consultative atmosphere while completing the task is also a remarkable opportunity in the teaching and learning journey. The way teachers give ongoing feedback, and the way students respond to these feedbacks build a social glue amidst the challenges brought about by the virtual platform. S6 acknowledged this as an important aspect, 
"...another lesson is that when creating your peta you must be consultative with your teachers so that they may guide you. In addition, I also learned that cramming is sometimes bad because you cannot consult since the deadline of the task is near...'

As cited from the work of Baser, et al (2017), the process of collaboration is the cornerstone of problem-based learning, which does not only provide room for constructing knowledge but also as a means of knowledge elicitation and internalization. This allows individuals to be immersed in the process of meaning-making that generate cognitive processes while working with others.

Space for Sense of Fulfillment. Being the first opportunity to adapt the integration activity, teachers felt a sense of fulfillment on executing the expectations of the performance task. The struggles and the new learning opportunities provided a new space of fulfillment in the roles that they played in the process. T6 shared,

Having finished this integration, I feel a sense of achievement both for me as a teacher and for my students for successfully accomplishing this task. It is not easy to combine science lessons with creative writing (and even harder to check), so I am glad to be able to say it's done.

Students also realized a changing mindset when it comes to being open-minded in taking constructive criticisms from teachers in revising their tasks and being responsive and humble enough to address the feedback and areas for improvement. As S1 testified,

"I was always scared about talking to my teachers and asking their opinion about my progress, but this kind of mindset changed during the PeTA integration. I realized that I should take constructive criticisms as an opportunity for my work to improve. Since I also love writing stories, this PeTA integration made my writing even better for my future works."

Areas for the Improvement of the PETA Integration. The integration between Science and English subjects proved to be a very challenging yet interesting experience for the students and the teachers. Despite challenges and difficulties, several opportunities were also evident and could make way for a better integrated task.

Emphasis on the foundational skills and knowledge for both subject areas should be a priority as it serves as the building blocks of the task. The in-depth teaching of character development, character traits, and story structure should be a focal topic in English. This will allow students to properly craft their characters utilizing the features of their assigned element. Likewise, science teachers can first provide base knowledge on the topic of elements. This would give the students foundational knowledge that will eventually help them accomplish the tasks, as these are all deemed an integral part in story construction.

Based on the teachers' responses, more consultation time should be allotted so that students can seek help, have their works reviewed, or even collaborate with other students with the objective of improving their work. In addition, a more flexible and possible longer timeline for the entire integrated task should be considered. This would allow more time for discussion of topics, both in Chemistry and in English, a prerequisite for doing the final output. Students have also suggested the possibility of having the task as a group output rather than an individual task. A model output could also be presented to the students. A written model could serve as a guide for the students so they can extract themes and writing patterns that can help them in writing their own story.

The Role of the Online Platform in Integrated Task. In addition, it was recognized in this undertaking the pros and cons in executing this kind of performance task in an online platform. The mechanism of coordination, communication, and consultation using the platform used was 
effective especially in assisting the students in responding to the feedback for the betterment of the output. Being a written output, students' way of communicating their expression and intentions in final output was also easier to assess in terms of authenticity since the checking mechanism in the LMS used has a similarity and plagiarism checker. Perceived challenges included the monitoring of the development of the output brought about by varying technological affordances and academic workloads of the students. In addition, possibility on questionable academic integrity in terms of the originality of the students' works can also be a hindrance to authentic learning. Facilitators of performance task like this need to creatively monitor the completion of the learners in the different stages of the task.

\section{IMPLICATIONS IN THE SCHOLARSHIP OF TEACHING AND LEARNING}

In an attempt to foster authenticity, creativity, interdisciplinarity, and personal meaningful learning experiences in the virtual setting, this pedagogical exploration offers insights in the field of teaching and learning and contributes to the literature in terms of the factors to be considered in merging the two disciplines without compromising the competencies to be addressed. As a form of collaborative inquiry, this practice harnesses diverse perspectives in terms of the nature of chemistry and language when it comes to meaningful integration. Acknowledging the extreme differences between the two, this innovation explores learners' creativity and critical thinking in weighing out the integrating points where the two subjects will meet. The outlined pedagogical procedures employed by the teachers in planning the task is a good opportunity to establish an organized practice in doing interdisciplinary outputs. Specifically, this paper offers the following implications:

a. As discussed in the paper, the role of foundational knowledge of the content and the manner of establishing collaboration with the learners in the development of the task are points for reflection in planning for performance tasks in different learning areas. One aspect that can be extracted from this observation is aside from identifying the competencies to be integrated, specific skills needed by both teachers and students should be outlined and contextualized by the integrating subjects. There is a need for participating teachers to immerse themselves in the expected competencies prior to assigning the students in performing the tasks.

b. The adoption of organized ways of communication and consultations among the students and the provision of consistent feedback in relation to the intentions of the tasks needs to be strengthened in relation to a strong foundational knowledge of the teachers who will guide the students in the completion of the output.

c. Considering that the expected task requires a separate skill especially on the part of the Chemistry subject, learning experiences in the formative stages must be anchored to it by exposing the learners with experiences that guide them to the skills expected in the outputs. Scaffolding the necessary skills and contents are crucial as the foundation of the performance task completion.

d. Pointing out the restriction on students' creativity brought about by the instruction to focus on the assigned element to be personified, flexibility in the guidelines can be done by giving the students the freedom to execute the tasks based on their choice, interests, and personality, alongside with the guidance of the teachers.

e. An assessment of the conceptual understanding of the students in relation to the task must be done after the completion of the performance task to validate as to whether the intended learning competencies were achieved. The model of conceptual change by Klassen (2010) can be adapted in which stories assist learners to process a conceptual change. This can be done by providing succeeding instructional interventions that would explore the students' conceptual understanding. 
Limitations and challenges to orchestrate the merging of the two disciplines are also recognized in the paper. Some areas can still be explored to figure out the impact of the task to the learners such as the inclusion of the actual measures of academic achievement of the learners and the conceptual understanding of the students in both subjects after completing the integrated task. In addition, accounting for other hidden learning experiences can also be explored to pave the way for new learning in the given context.

\section{REFERENCES}

Alber M. Creative writing and chemistry. J Chem Educ. 2001 April; 78(4), 478. https://doi.org/10.1021/ed078p478

Bradbury LU. Linking science and language arts: A review of the literature which compares integrated versus non-integrated approaches. J Sci Teach Educ. 2014 Jun; 25(4):465-488 https://doi.org/10.1007/s10972-013-9368-6

Baser D, Ozden MY, Karaarslan H. Collaborative project-based learning: An integrative science and technological education project. Res Sci Technol Educ. 2017 Jan; 35(2):131-148. https://doi.org/10.1080/02635143.2016.1274723

Crawford J, Butler-Henderson K, Rudolph J, Malkawi B, Glowatz M, Burton R, Magni P, Lam S. COVID-19: 20 countries' higher education intra-period digital pedagogy responses. J Appl Learn Teach. 2020 Apr; 3(1):1-20. http://dx.doi.org/10.37074/jalt.2020.3.1.7

Danckwardt-Lillieström K, Andrée M, Enghag M. The drama of chemistry-supporting student explorations of electronegativity and chemical bonding through creative drama in upper secondary school. Int J Sci Educ. 2020 Aug; 5:1-33. https://doi.org/10.1080/09500693.2020.1792578

DepEd. Most Essential Learning Competencies. 2020. https://commons.deped.gov.ph/melc

Edelen J. Creating successful learners through arts integration. Childhood Educ. 2020 Oct; 96(5):44-5. https://doi.org/10.1080/00094056.2020.1824505

Engel A, Lucido K, Cook K. Rethinking narrative: Leveraging storytelling for science learning. Childhood Educ. 2018 Oct; 94(6):4-12. https://doi.org/10.1080/00094056.2018.1540189

Fishman E. Inviting narrative back into the science classroom: Telling the stories of the elements with graphic novels. School Sci Rev. 2020 Sep; 102(378):78-82. https://www.ase.org.uk/system/files/SSR September 2020 078-082 Fishman.pdf

Freire M, McCarthy E. Four approaches to new media art education. Art Educ. 2014 Mar; 67(2):2831. https://doi.org/10.1080/00043125.2014.11519262

Furlan PY, Kitson H, Andes C. Chemistry, poetry, and artistic illustration: an interdisciplinary approach to teaching and promoting chemistry. J Chem Educ. 2007 Oct; 84(10):1625. https://doi.org/10.1021/ed084p1625

Gillen CM, Kerkhoff AJ, Lynn DH, McFarlane HG, Niemiec AJ, Petersen SC, Reach AD. Does creative writing improve scientific writing and learning? The FASEB J. 2020 Apr; 34(S1):1-1. https://doi.org/10.1096/fasebj.2020.34.s1.05351 
Helmane I, Briška I. What is developing integrated or interdisciplinary or multidisciplinary or transdisciplinary education in school? Signum Temporis, 2017; 9(1):7-15. http://archive.sciendo.com/SIGTEM/sigtem.2017.9.issue-1/sigtem-2017-0010/sigtem-20170010.pdf

Hu J, Gordon C, Yang N, Ren Y. "Once upon a star": A science education program based on personification storytelling in promoting preschool children's understanding of astronomy concepts. Early Educ Dev. 2021; 32(1):7-25. https://doi.org/10.1080/10409289.2020.1759011

Januchowski-Hartley SR, Sopinka N, Merkle BG, Lux C, Zivian A, Goff P, Oester S. Poetry as a creative practice to enhance engagement and learning in conservation science. BioScience. 2018 Nov; 68(11):905-911. https://doi.org/10.1093/biosci/biy105

Kedraka K, Kaltsidis C. Effects of COVID-19 pandemic on university pedagogy: Students' experiences and considerations. Eur J Educ Studies. 2020 Jul; 7(8):17-29. http://dx.doi.org/10.46827/ejes.v7i8.3176

Klassen S. The relation of story structure to a model of conceptual change in science learning. Sci Educ. 2010; 19(3):305-317. https://doi.org/10.1007/s11191-009-9212-8

Knobel M, Lankshear C. Remix: The art and craft of endless hybridization. J Adolesc Adult Lit. 2008 Sep; 52(1):22-33. https://doi.org/10.1598/JAAL.52.1.3

Kolovou M, Kim NJ. Effects of implementing an integrative drama-inquiry learning model in a science classroom. J Educ Res. 2020 Apr; 113(3):191-203. https://doi.org/10.1080/00220671.2020.1771673

Lansangan RV. Teaching Junior High School Chemistry During the COVID-19 Community Quarantine Season: Lessons, Challenges, And Opportunities. KIMIKA. 2020 May; 31(1):20-37. https://doi.org/10.26534/kimika.v31i1.20-37

Lansangan RV, Gonzales KP. Science teachers' voices in the new normal teaching: A phenomenological study. IOER Int Multidiscip Resp J. 2020 Oct; 2(3):124-32. http://doi.org/10.5281/zenodo.4062840

Loomis SJ. Remixing pedagogy: How teachers experience remix as a tool for teaching english language arts. Dissertation, Georgia State University, 2019. https://scholarworks.gsu.edu/mse diss/82

Lynn MA, Templeton DC, Ross AD, Gehret AU, Bida M, Sanger TJ, Pagano T. Successes and challenges in teaching chemistry to deaf and hard-of-hearing students in the time of COVID-19. J Chem Educ. 2020 Aug; 97(9):3322-3326. https://doi.org/10.1021/acs.jchemed.0c00602

Mishra L, Gupta T, Shree A. Online teaching-learning in higher education during lockdown period of Covid-19 pandemic. Int J Educ Res Open. 2020 Sep; 1:100012. https://doi.org/10.1016/j.ijedro.2020.100012

Mojica ER. A personal account of teaching chemistry courses in the epicenter of the COVID-19 pandemic. KIMIKA. 2020 Aug 5; 31(2):1-0. https://doi.org/10.26534/kimika.v31i2.1-10

Morris SM, Stommel J. An urgency of teachers: The work of critical digital pedagogy. Chicago: Hybrid Pedagogy Inc; 2018.

Navas E, Gallagher O, Burrough X, editors. Keywords in remix studies. New York, NY: Routledge. 2017. https://doi.org/10.4324/9781315516417 
Niemi HM, Kousa P. A case study of students' and teachers' perceptions in a Finnish high school during the COVID pandemic. Int J Technol Educ Sci. 2020 Sep; 4(4): 352-369. https://doi.org/10.46328/ijtes.v4i4.167

Pace C, Pettit SK, Barker KS. Best practices in middle level quaranteaching: Strategies, tips and resources amidst COVID-19. Becoming: J Georgia Assoc Middle Level Educ. 2020 May; 31(1):2. https://doi.org/10.20429/becoming.2020.310102

Potgieter M, Pilcher LA, Tekane RR, Louw I, Fletcher L. Lessons learnt from teaching and learning during disruptions. In: Schultz M, Schmid S, Lawrie G, editors. Research and practice in chemistry education: Advances from the 25th IUPAC International Conference on Chemistry Education 2018; Singapore: Springer; 2019. p. 89-107. https://link.springer.com/chapter/10.1007/978981-13-6998-8 6

Putri RS, Purwanto A, Pramono R, Asbari M, Wijayanti LM, Hyun CC. Impact of the COVID-19 pandemic on online home learning: An explorative study of primary schools in Indonesia. Int J $\begin{array}{llll}\text { Advanced } & \text { Sci } & \text { Technol. 2020: } & \text { 29(05):4809-4818. }\end{array}$ http://sersc.org/journals/index.php/IJAST/article/view/13867

Redmond T, Henson J. The transcendent power of remix: Cultivating creativity, story, and student voice in online learning. In: Ferdig RE, Baumgartner E, Hartshorne R, Kaplan-Rakowski R, Mouza C, editors. Teaching, technology, and teacher education during the COVID-19 pandemic: Stories from the field. Association for the Advancement of Computing in Education (AACE); 2020. 77-84 p. https://www.researchgate.net/publication/344929880 The transcendent power of remix Cultivating creativity story and student voice in online learning

Reimers F, Schleicher A, Saavedra J, Tuominen S. Supporting the continuation of teaching and learning during the COVID-19 Pandemic. OECD. 2020 Jul 17; 1(1):1-38. https://www.oecd.org/education/Supporting-the-continuation-of-teaching-and-learningduring-the-COVID-19-pandemic.pdf

Rootman-le Grange I, Retief L. Action research: integrating chemistry and scientific communication to foster cumulative knowledge building and scientific communication skills. J Chem Educ. 2018 June; 95(8):1284-1290. https://doi.org/10.1021/acs.jchemed.7b00958

Schettino V. Science and art. Chemistry, fine arts and literature. Rendiconti Lincei. 2014 Sep; 25(3):327-338. https://doi.org/10.1007/s12210-014-0318-9

Tan HR, Chng WH, Chonardo C, Ng MT, Fung FM. How chemists achieve active learning online during the COVID-19 pandemic: Using the community of inquiry (CoI) framework to support remote teaching. J Chem Educ. 2020 Jul; 97(9):2512-2518. https://doi.org/10.1021/acs.jchemed.0c00541

Tigaa RA, Sonawane SL. An international perspective: Teaching chemistry and engaging students during the COVID-19 pandemic. J Chem Educ. 2020 Jul; 97(9):3318-3321. https://doi.org/10.1021/acs.jchemed.0c00554

Toquero CM. Challenges and opportunities for higher education amid the COVID-19 pandemic: The Philippine context. Pedagog Res. 2020 Apr; 5(4): em0063. https://doi.org/10.29333/pr/7947 
Tournis AJ, Dipinto VM. “... It was a terrible mistake!” Science, chemistry, and storytelling. In Johnson AF, Odeleye 00, editors, Chemistry Student Success: A Field-Tested, Evidence-Based Guide 2020. American Chemical Society. P. 137-151. https://doi.org/10.1021/bk-20201343.ch009

Wu Z. How a top Chinese university is responding to coronavirus. InWorld Economic Forum 2020. https://www.weforum.org/agenda/2020/03/coronavirus-china-the-challenges-of-onlinelearning-for-universities/

Yang C, Lee J, Noh T. An exploratory investigation of the imaginative writing processes of middle school students. J Korean Assoc Sci Educ. 2014 Aug; 34(5):511-521. http://dx.doi.org/10.14697/jkase.2014.34.5.0511 